\title{
MUDANÇAS SUBJETIVAS DE UM ESTUDANTE NUMA OFICINA DE CIÊNCIAS \\ E SUA ARTICULAÇÃO COM A DINÂMICA GRUPAL E O PAPEL DAS INTERVENÇÕES DA PROFESSORA
}

\author{
Subjective changes in a student performance \\ after a science workshop and its articulation with the \\ group dynamics and the role of the teacher's intervention
}

\author{
Marcelo Alves Barros ${ }^{1}$. Zenaide de Fátima \\ Dante Corrêa Rocha ${ }^{2}$. Carlos Eduardo Laburú ${ }^{3}$
}

\begin{abstract}
Resumo: O objetivo desse trabalho consiste em investigar as mudanças subjetivas de um estudante durante a realização de uma Oficina de Ciências e articulá-las, por um lado, com os discursos da professora e, por outro, com a dinâmica de funcionamento grupal. Os dados foram coletados numa escola pública do município de Londrina/PR. No total foram realizados quinze encontros, e o instrumento de coleta de dados consistiu na gravação em vídeo. O grupo selecionado para a pesquisa constituiu-se de quatro alunos do II Ciclo ( $3^{\mathrm{a}}$ e $4^{\mathrm{a}}$ séries) do Ensino Fundamental. O referencial teórico utilizado para análise e interpretação dos dados encontra sua base em conceitos psicanalíticos de orientação lacaniana e da dinâmica de grupos. Concluímos considerando alguns aspectos que podem contribuir para a promoção e sustentação da aprendizagem em grupo em situações de ensino, sinalizando para o papel das intervenções do professor no sentido de promover um trabalho colaborativo.
\end{abstract}

Palavras-chave: Subjetividade. Ensino de Ciências. Grupo de Aprendizagem.

\begin{abstract}
The aim of this work is to investigate the subjective changes of students during the performance of a science workshop and to articulate them, to include both the discourse of the teacher, and the dynamics of learning groups. Data were collected in a public school in Londrina/PR. In total fifteen meetings were conducted and the data collection instrument consisted of recording on video. The group selected for the study consisted of four students in Cycle II ( $3^{\text {td }}$ and $4^{\text {th }}$ grades) of Elementary School. The theoretical framework used for analysis and interpretation of their data is based on Lacanian psychoanalytic concepts and the dynamics of groups. The conclusions were that some aspects can help to promote and support learning in groups in situations of teaching, and signaling for assistance from the teacher promotes collaborative work.
\end{abstract}

Keywords: Subjectivity. Science Teaching. Learning Group.

\footnotetext{
${ }^{1}$ Instituto de Física, Universidade de São Paulo (USP). Avenida Trabalhador São-carlense, 400. Caixa Postal 369. São Carlos, SP, Brasil. 13.560-970. Com apoio do CNPq e Fapesp. mbarros@ifsc.usp.br

${ }^{2}$ Universidade Estadual de Campinas (Unicamp). Campinas, SP, Brasil.

${ }^{3}$ Departamento de Física, Universidade Estadual de Londrina (UEL). Londrina, PR, Brasil. Com apoio do CNPq e da Fundação Araucária.
} 
Barros, M. A.; Rocha, Z. F. D. C.; Laburú, C. E.

\section{Introdução}

Nas últimas três décadas do século XX, o desenvolvimento das pesquisas na área de educação científica teve como resultado a elaboração teórica conhecida pelo nome de modelo de mudança conceitual. Esse modelo passou a ser uma proeminente referência (DUIT, 2003) para a compreensão do processo de aprendizagem científica e de encaminhamento de propostas para o ensino de ciências. Surgido a partir do movimento das concepções alternativas nos fins dos anos setenta, o modelo de mudança conceitual constrói seus fundamentos baseados na Filosofia da Ciência (POSNER et al., 1982) e na Psicologia Cognitiva (OSBORNE; WITTROCK, 1983).

Porém, nos últimos anos, pesquisas em educação matemática e científica (SOLOMON, 1989; CONFREY, 1990; STRIKE; POSNER, 1992; PINTRICH; MARK; BOYLE, 1993; MORTIMER, 1995; VILLANI; CABRAL, 1997; MORTIMER; SCOTT, 2002; MOREIRA, 2002; LABURÚ; CARVALHO, 2005; DUVAL, 2006) vêm concentrando esforços para superar essa visão de aprendizagem como mudança conceitual, propondo novas metodologias de ensino.

Neste artigo nos interessa, em especial, uma linha de pesquisa que vem se desenvolvendo no Brasil e que busca contribuições da Psicanálise para salientar elementos de natureza inconsciente na conduta de alunos e professores durante as aulas de ciências (BAROLLI, 1998; ARRUDA, 2001; BARROS, 2002; VALADARES, 2002; SANTANA, 2003; FRANZONI, 2004; VILLANI et al., 2004; ROCHA, 2005). Estes pesquisadores têm ressaltado a importância da subjetividade como aspecto que não pode ser negligenciado na aprendizagem das ciências, se pretendemos avançar em nossa capacidade explicativa da dinâmica da sala de aula, a partir da explicitação de elementos que ultrapassam o campo cognitivo.

Apesar dos avanços significativos desta perspectiva de analogia entre um processo de análise individual e/ou grupal e um processo de aprendizagem, as pesquisas realizadas até o momento têm se concentrado exclusivamente no Ensino Médio e Superior, sendo praticamente inexistentes trabalhos que exploraram as potencialidades deste referencial teórico na interpretação de situações didáticas entre alunos e professores no Ensino Fundamental.

Este trabalho visa contribuir nesta direção, no sentido de investigar as mudanças subjetivas de um estudante e articulá-las com a dinâmica de funcionamento de um grupo de aprendizagem, assim como com as intervenções da professora. Mais especificamente, buscaremos identificar alguns condicionantes subjetivos que caracterizam as diferentes posições que um estudante ocupa frente ao conhecimento, à professora e aos colegas durante a realização de atividades de conhecimento físico numa Oficina de Ciências no Ensino Fundamental.

\section{Referencial teórico}

Neste trabalho, utilizaremos um esquema teórico elaborado com base em conceitos da psicanálise de orientação lacaniana (FINK, 1998), denominado perfil subjetivo, e outro esquema relacionado à dinâmica grupal, inspirado nos conceitos da psicanálise de grupos (ANZIEU, 1993), denominado de organizadores psíquicos inconscientes de grupo. 


\section{O perfil subjetivo}

Os elementos fundamentais deste esquema são um conjunto de categorias, referentes à posição do aluno em relação ao conhecimento científico, denominadas de patamares subjetivos de aprendizagem (VILLANI; BAROLLI, 2000); e um correspondente conjunto de categorias, referentes à metodologia de ensino adotada pelo professor, denominadas de captura por discursos (ARRUDA, 2001). O perfil subjetivo de um aluno é dado pela adesão relativa a cada patamar de aprendizagem, e o de um professor, por sua captura por um determinado discurso institucional.

\section{Patamares subjetivos de aprendizagem}

Envolvem as relações explícitas e implícitas dos estudantes com o conhecimento científico, o professor, os colegas e o restante da sociedade, sendo classificados em sete tipos diferentes:

. Rejeição direta: o conhecimento escolar é rejeitado ou desprezado. A recusa ao conhecimento transparece pela falta de interesse e motivação frente às atividades propostas pelo professor, que é, algumas vezes, simplesmente ignorado.

- Indecisão: os alunos oscilam entre a rejeição e a aceitação do conhecimento e na entrega ao professor. Algumas vezes, parecem aderir às atividades didáticas, mas, outras vezes, procuram o mínimo esforço para satisfazer as aparências.

. Demanda passiva: os alunos têm total confiança que o conhecimento lhes será transferido com pouco esforço. O conhecimento, para eles, é apenas algo que se recebe, e a regra básica do jogo é aprender as respostas corretas. A situação é de dependência total em relação ao professor.

- Risco: os alunos demonstram maior participação e aceitam mostrar o seu conhecimento. Entretanto, isso se dá mais pela satisfação em se fazer notar pelo professor e em se destacar perante os colegas do que em procurar o conhecimento.

- Aprendizagem ativa: os alunos já aceitam procurar pelas respostas e o conhecimento é algo que se deve adquirir através do esforço. $O$ aluno trabalha para satisfazer o desejo do professor e ser por ele reconhecido.

- Avanço: os alunos começam a experimentar um trabalho original de pesquisa, mas ainda permanece a satisfação em serem reconhecidos pelo professor, o qual ainda é colocado na posição de uma autoridade a quem recorrer em caso de maiores dificuldades.

- Procura criativa: é caracterizada pela resolução de problemas e produção de um novo conhecimento de forma autônoma pelos alunos. O professor passa a ser mais um assessor, ajudando os alunos a localizarem e avaliarem as informações.

\section{Captura por discursos institucionais}

Refere-se aos diferentes tipos de discursos institucionais que capturam o professor e orientam suas ações em sala de aula, também sendo classificados em sete tipos diferentes:

- Discurso do consumo: introduz demandas que nada têm a ver com a procura de conhecimento científico. $\mathrm{O}$ trabalho do professor é visto como uma mera complementação salarial, e há ausência de compromisso com a profissão. 
- Discurso da burocracia: demanda o cumprimento dos ritos burocráticos que garantem as aparências e leva o professor a não se posicionar frente aos problemas reais da escola. Importa mais cumprir as regras do que ensinar os alunos, sempre encontrando dificuldades e poucas condições para a realização de seu trabalho.

. Discurso do conhecimento científico: privilegia o conhecimento científico, os manuais e os livros-texto. O papel do professor é tornar-se a fonte do conhecimento e transmiti-lo aos alunos, identificando-se com a figura do mestre que detém o conhecimento a ser ensinado.

- Discurso do conhecimento metodológico: o professor parece procurar um método à prova de suas próprias falhas, que funcione pelas suas qualidades intrínsecas, uma "nova maneira de ensinar". Basta achar os elementos adequados e o ensino torna-se uma tarefa fácil e agradável.

. Discurso do conhecimento reflexivo: corresponde à adesão ao conhecimento teórico e prático sobre a aprendizagem em ciências, que enfatiza a necessidade de participação ativa do aluno em sua aprendizagem. Focaliza a atividade reflexiva do professor, para que ele possa acompanhar a evolução da aprendizagem de seus alunos.

- Discurso da pesquisa orientada: sua ênfase é a crítica ao conhecimento estabelecido e a produção de novo conhecimento. Surge sob orientação de um pesquisador mais experiente, ou seja, num contexto de prestar conta para alguém e/ou para um determinado referencial que não está sujeito à contestação.

- Discurso da pesquisa autônoma: é o discurso da criação, da elaboração de algo inédito, sem a necessidade de prestar conta para uma instância superior. O professor capturado por esse discurso age como um assessor de seus alunos, ajudando-os em suas escolhas e reconhecendo suas autonomias.

\section{Organizadores psíquicos inconscientes de grupo}

A ideia de organizadores psíquicos inconscientes de grupo (ANZIEU, 1993) nos permite analisar um grupo do ponto de vista dele mesmo, e não dos indivíduos isoladamente. Apesar de os indivíduos exercerem papéis específicos num grupo, eles obedecem a uma forma de organização inconsciente que dá unidade e integração ao grupo. Tais organizadores estão estruturados em cinco tipos:

- Fantasma individual: no início da formação de um grupo, os indivíduos sentem-se ameaçados de perderem sua individualidade e, como defesa a essa ameaça, unem-se ao redor de um elemento psíquico de um membro do grupo, denominado fantasma individual, ocasionando um fenômeno que pode ser descrito como uma fusão indiscriminada de todos os membros entre si.

- Imago: A imago é um protótipo inconsciente de um personagem que, no indivíduo, permanece a partir de figuras internalizadas ao longo de sua vida. Um grupo organizado por uma imago se une não mais em torno do fantasma individual de um dos seus membros, possibilitando maior diferenciação entre os integrantes do grupo.

. Fantasma originário: As fantasias originárias são as que surgem a partir do nascimento; e um grupo organizado em torno de um fantasma originário admite ter uma origem comum, de modo a tolerar as diferenças entre seus membros, fazendo com que os papéis não sejam mais estabelecidos de modo fixo e imutável. 
Mudanças subjetivas de um estudante ...

- Complexo de Édipo: trata-se de um organizador específico do grupo familiar. Ele opera a diferenciação entre o grupo-família (heterogêneo e natural) e o grupo-associação (homogêneo e cultural).

- Imagem do corpo único: para se separar o mundo exterior do interior, para colocálos em contato, para filtrar suas trocas, para conter o que está no interior, é preciso que se constitua uma espécie de envelope-grupal, uma superfície, ao mesmo tempo delimitativa, protetora, envolvente, imunitária, e que se faça fonte ativa de iniciativas.

\section{Metodologia de pesquisa}

Esta pesquisa é de natureza qualitativa (BOGDAN; BIKLEN, 1994), e trata-se de um estudo de caso sobre as mudanças subjetivas de um estudante durante a realização de uma Oficina de Ciências.

Os dados foram coletados mediante gravação dos encontros em vídeo, numa escola pública do município de Londrina, PR. Ao total, foram realizados 15 encontros com uma turma constituída por 12 alunos. Os encontros aconteceram exclusivamente com os alunos organizados em grupos fixos e formados espontaneamente. $\mathrm{O}$ grupo selecionado para a filmagem era constituído por quatro alunos (CA, JE, JA e PE) com idade entre nove e dez anos. A professora era a própria investigadora, e os encontros ocorriam no laboratório de ciências da escola uma vez por semana, com duração de uma hora e trinta minutos.

Neste trabalho, apresentamos três atividades de ensino que são representativas dos eventos que marcaram as correspondentes mudanças subjetivas de um destes estudantes ao longo do tempo. Os resultados apresentados complementam aqueles encontrados em outros trabalhos (BARROS et al., 2005; BARROS; LABURÚ; ROCHA, 2007) que priorizaram aspectos subjetivos na análise de diversas situações de ensino em sala de aula.

\section{Análise e interpretação dos dados}

\section{Atividade dos carrinhos}

A atividade dos carrinhos (BARROS et al., 2005) ocorreu no primeiro encontro, e consistia em colocar em movimento um carrinho de plástico que possuía uma bexiga acoplada na parte traseira.

O convite inicial: a professora convidou os alunos a participarem de uma competição na qual venceria o grupo que conseguisse fazer o seu carrinho percorrer uma distância fixa em menos tempo. Cada grupo poderia utilizar somente um carrinho para a competição, embora recebessem três para poder testá-los e escolher o melhor. A presença, no grupo, de quatro alunos implicava a necessidade de terem de compartilhar o material, o que, eventualmente, poderia tornar explícitos os conflitos vivenciados por eles na resolução da tarefa. Assim, após testarem os carrinhos com as bexigas, a professora propôs aos alunos escolherem apenas um carrinho e definirem um representante para utilizar o carrinho escolhido para competir entre os grupos. 
O convite da professora estabeleceu um novo clima na classe. Ela vislumbrava certamente despertar o interesse e a participação dos alunos; visava também a troca de materiais e de ideias entre eles, assim como a exploração da atividade em conjunto e a constituição de grupos organizados de aprendizagem. No entanto, ela não explicitou essas finalidades, nem enfatizou quanto a colaboração favoreceria a qualidade do resultado obtido. Desejava estabelecer, em seu curso, o discurso do conhecimento reflexivo, mas mantinha-se capturada pelo discurso metodológico, o qual estava acostumada a exercer em sua prática docente. Os membros do grupo estavam se familiarizando com o novo contexto de aprendizagem, pois, para todos, era uma novidade: a realização de atividades diferenciadas na oficina de ciências, o contato com uma professora e com colegas diferentes. Desta forma, cada membro começava as tentativas de forma individualizada procurando atender ao discurso da professora. Para os alunos, o objetivo era vencer a competição e serem reconhecidos pela professora e pelos colegas. Não há evidências de que, para eles, a vitória estivesse associada à construção de uma intensa colaboração grupal.

Nesta etapa, cada membro do grupo permanecia totalmente dependente das diretrizes da professora. Em particular, o aluno JE parecia não compreender a metodologia de trabalho a qual a professora desejava orientar. De certa forma, este aluno projetava a real necessidade do grupo, que solicitava implicitamente a orientação clara e precisa da professora sobre o trabalho que deveriam realizar. A atividade era vista como objeto de consumo, não sendo considerada como instrumento de pensamento para aplicações semelhantes no cotidiano. A crença do grupo se fundamentava na esperança de que a professora lhe fornecesse a capacidade de resolução do problema proposto, ao facilitar e organizar caminhos para a solução desejada. A professora ocupava o lugar de outro ${ }^{4}$, do qual tudo se esperava. A ela era atribuída a responsabilidade do progresso ou do fracasso do grupo em solucionar o desafio. Essa relação entre a professora e o grupo foi marcada por uma dependência total. A satisfação do grupo estava em manter-se na dependência passiva em relação ao saber e se alimentar da atenção fornecida pela professora, dinâmica na qual estavam habituados. Ela era vista pelos membros do grupo como a responsável pelo direcionamento das ações que envolveriam a atividade e a garantia de que a solução do desafio lhes seria fornecida, independentemente de qualquer circunstância.

A constituição de um subgrupo: inicialmente PE ficou sem o carrinho. JA e JE não se deram conta de que o colega necessitava de um carrinho para fazer suas tentativas e continuaram testando seus carrinhos individualmente; mas CA, logo após a sua primeira tentativa, ofereceu o seu carrinho a PE. Esta atitude facilitou a comunicação entre eles em torno da tarefa: trocaram ideias e experimentaram o carrinho com o objetivo de controlar seu funcionamento. Logo em seguida, JA percebeu que os outros dois colegas estavam trabalhando em conjunto, então, decidiu colaborar já visando obter um bom desempenho do carrinho e seleci-

${ }^{4}$ Leia-se "grande outro" (LACAN, 1995). O “outro" refere-se à fonte dos significantes marcantes dos indivíduos, lugar que pode ser ocupado provisoriamente por figuras ou elementos relacionados com a escola ou o contexto sociocultural. Indica a referência implícita da criança, introduzida quando de sua entrada na linguagem (FINK, 1988). Inicialmente, seus representantes são os pais, posteriormente, qualquer instância social que a capture. 
onar o melhor para a competição. Com isso, JA, CA e PE começaram a interagir coletivamente, com frequentes trocas de materiais e de opiniões sobre as maneiras de colocar as bexigas e sobre as características dos carrinhos utilizados. Por sua vez, JE se afastou do grupo e se isolou dos colegas, não querendo compartilhar o seu carrinho com os outros. Ao explicar como fazer para o carrinho andar mais rápido, JA se dirigia exclusivamente aos colegas CA e $\mathrm{PE}$, que ouviam atentamente suas explicações, ignorando a presença de JE.

JA: Sabe como a gente tem que faz̧er para o carrinho andar mais rápido!? Olha, a gente pega esse bocal aqui e coloca assim ó (ele pega no bocal e sopra forte dentro dele enchendo a bexiga de ar) depois a gente enche a bexiga, segura o bocal com o dedo e solta.

Os alunos PE e CA observavam atentamente a demonstração de JA e, logo depois, retomavam o teste dos carrinhos, revezando os carrinhos entre si e tentando aprimorar suas ações a partir do que JA havia sugerido.

Podemos dizer que o subgrupo formado por JA, CA e PE foi fundado neste momento, mediante estabelecimento de um vínculo entre eles; por sua vez, JE ficou excluído da discussão e da troca de materiais. Parece claro que JA tornou-se a primeira liderança do grupo capaz de estabelecer um contrato narcísico (constituir um grupo vitorioso), coordenando as atividades nesse sentido. Junto com esse contrato podemos reconhecer, também, um pacto implícito (não deixar que as agressividades individuais perturbassem o trabalho conjunto de testes).

O subgrupo liderado por JA caracterizou-se, nesse momento, por uma nova configuração entre os membros, que selaram um compromisso com a resolução do desafio. Em contrapartida, JE continuou agindo de forma individualizada e acabou se isolando dos demais.

Um episódio marcante ocorreu no momento em que o grupo teve de escolher o melhor carrinho para a competição, pois eles precisavam comparar os carrinhos e decidir a respeito. JE, pela primeira vez, sentiu-se pressionado a participar do grupo, embora insistisse em não compartilhar o seu carrinho com ninguém.

As tentativas de ampliar o grupo: JA conversou com JE na tentativa de integrá-lo à tarefa, argumentando sobre a importância de testarem o carrinho e vencerem a competição.

JE: Esse carrinho aqui é bom (mostrou o carrinho que ele estava utilizando desde então).

JA: Deixa en ver se esse carrinho ai é melhor para a gente competir (estende a mão em direção a JE para pegar o carrinho).

JE: Não, deixa que eu mostro (segurando o carrinho entre as mãos junto ao corpo).

JA: Dá aí, vamos logo, senão a gente vai perder (JE fica em silêncio por alguns segundos).

JE: Espera né.

JE acabou cedendo ao argumento de JA, porém, ainda com resistências, reveladas por sua expressão corporal (ele empurrou JA e protegeu o carrinho junto ao seu corpo). Logo em seguida, permitiu que JA pegasse o carrinho para testar, talvez pela necessidade de unir-se aos 
colegas para vencer a corrida: o contrato narcísico começava a capturar também JE. Mesmo que o grupo tenha exercido pressão, JE aderiu à tarefa de forma cooperativa quando percebeu que o grupo corria o risco de perder a competição caso não escolhesse o melhor carrinho. As necessidades de resolver o desafio e o interesse em vencer a competição uniram JE ao grupo.

A aluna CA também se mostrava colaborativa com JE, dando-lhe atenção e explicando os truques para fazer o carrinho andar mais rápido. Quando JE encontrou dificuldade para ajustar o bocal, JA ofereceu-lhe ajuda, que, inicialmente, foi recusada, mas, em seguida, aceita.

CA: Você tem que arrumar esse negocinho aqui (mostra o bocal) bem reto, depois enche bem e segura bem forte para não escapar, e coloca no chão bem certinho assim (demonstra colocando o carrinho alinhado no chão e solta-o). JE: Isso daqui não pára certo (refere-se ao bocal).

JA: Deixa eu ver pra você.

JE: Não, deixa que en arrumo.

JA: Mas você tem que puxar para fora! Deixa en tentar?

JA tentou pegar o carrinho, JE ficou bravo e o empurrou para que não se aproximasse, puxando o seu carrinho com violência e justificando que ele mesmo desejava resolver esse problema. Como não estava conseguindo, acabou aceitando a ajuda de JA. Com um gesto de quem permite ser auxiliado, deu o carrinho para JA e permaneceu observando com atenção como ele arrumava o bocal.

Inicialmente, percebemos que os alunos buscavam apoio, para a resolução do desafio, basicamente na professora, pois mantinham com ela uma transferência do tipo imaginária ${ }^{5}$ (FINK, 1998). Quando o subgrupo se organizou em torno de já, este aluno tornou-se um líder capaz de organizar o subgrupo em torno da atividade proposta e forneceu abertura para a inclusão de JE. Simultaneamente, JE transitou entre os patamares de indecisão e demanda passiva, demonstrou sua necessidade de ficar brincando com o carrinho individualmente, e, quando se sentiu pressionado pelo grupo, respondeu de forma agressiva e egoísta. Entretanto, o subgrupo acabou convencendo-o de que os objetivos de vencer a competição eram comuns a todos. Então, JE abriu-se à mudança e passou a compartilhar suas ações com as dos demais colegas.

O processo de inclusão de JE, importante para poder maximizar as chances de vitória, deu-se graças à habilidade do grupo em contornar a agressividade dele e convencê-lo sobre as vantagens da colaboração. O episódio mostrou claramente a força do pacto implícito do subgrupo de recalcar as agressividades, e sua vontade de vitória que acabou sendo compartilhada também por JE. As regras de colaboração, que dariam maiores chances para o grupo escolher o melhor carrinho, começaram a serem respeitadas por todos, mesmo que com diferentes graus de adesão pessoal.

\footnotetext{
${ }^{5}$ Corresponde à situação do professor que é colocado na posição de mestre-todo por seus alunos. Nesse caso, podemos falar de uma situação caracterizada pela instalação de uma transferência imaginária, caso em que os alunos, supondo que o professor possui um certo saber que lhes falta, imaginam que este tenha a chave para resolver seu problema.
} 
Um avanço: quando a professora pediu que os grupos escolhessem seu representante para participar da corrida, os membros do grupo concordaram em realizar um sorteio, e PE foi o escolhido para representar o grupo. Este não ganhou a competição, deixando todos os membros frustrados; JE tentou reagir pedindo, autoritariamente, para todos os colegas e a professora, que se fizesse uma nova corrida, esperando, desse modo, ter uma nova chance de vitória. A classe não aceitou sua reivindicação, porém os colegas JA e PE mostraram-se solidários a JE e, também, pediram uma nova corrida. No entanto, com a recusa da classe, desistiram, percebendo, aparentemente, que estavam violando as regras combinadas. Ao final, JE acabou sorrindo e concordando com o resultado.

JE, inicialmente, resistiu ao trabalho coletivo e acabou se isolando dos colegas. JA assumiu o papel de líder e tomou a iniciativa quanto à resolução do desafio, convocando o grupo para a ação. CA e PE apresentaram-se cooperativos, reconheceram JA como líder do grupo e agiram com flexibilidade durante a realização da tarefa, mas JE avançou apenas quando se deu conta de que seu objetivo era comum ao objetivo do subgrupo.

Do ponto de vista da dinâmica grupal, podemos afirmar que o grupo esteve, até este momento, organizado em torno do fantasma individual do líder. Estabeleceu-se uma transferência do tipo imaginária com a professora, que acreditavam estar ali para dar as respostas prontas para eles, evitando, assim, que experimentassem algum sofrimento. Embora todos estivessem mobilizados pela atividade e demonstrassem interesse em solucionar o problema, JE só foi convidado a participar do grupo frente à urgência em definir qual carrinho disputaria a competição. Podemos inferir que, a partir desse momento, houve uma mudança de configuração do grupo, pois pudemos perceber uma mudança no papel desempenhado por JE. Esse aluno, inicialmente, desempenhou um papel individual marcado por muita agressividade e sua não-participação no grupo, constituindo-se num obstáculo para a coesão do grupo que, inconscientemente, vivenciou isso como uma ameaça para a sua manutenção.

A atividade de ensino, isto é, vencer a corrida, exerceu um forte apelo para a integração de JE no grupo, atuando, também, como um intermediário ${ }^{6}$ (KAËS, 1997) entre o patamar de indecisão e o patamar de demanda passiva. Ele passou a exercer um novo papel caracterizado pela realização da tarefa em comum e a manutenção do grupo. Esse fato produziu um efeito positivo no grupo, que passou a trabalhar de forma mais satisfatória e cooperativa.

\section{Atividade do copo}

A atividade do copo (BARROS; LABURÚ; ROCHA, 2007) ocorreu no sexto encontro, e tinha como objetivo discutir a existência do ar e do espaço ocupado por ele. O desafio consistia em colocar uma folha de papel dentro de um copo e afundar o mesmo dentro de uma vasilha com água, sem molhar o papel.

\footnotetext{
${ }^{6}$ O conceito de intermediário é proposto por Kaës (1997) como mecanismo de passagem, isto é, como um conector em um momento de ruptura entre os laços que mantêm as relações intersubjetivas e/ou entre dois espaços heterogêneos. Esse intermediário, que pode ser inclusive uma ideia, é construído para assegurar os apoios narcísicos necessários para o desenvolvimento tanto do sujeito como do grupo, isto é, para dar condições ao sujeito de encontrar um lugar no qual ele seja investido pela nova forma de trabalho proposta.
} 
Em encontros anteriores, JE mantinha, com maior frequência, um papel menos privilegiado no grupo, era o último a fazer as tentativas para a resolução do desafio, não se integrava com os demais membros e apresentava mais dificuldades para compreender as formas de resolução dos desafios lançados pela professora ao grupo. Os colegas o ignoravam e ele percebia isso. No início do sexto encontro, a dinâmica do grupo parecia semelhante à dos encontros anteriores, JA liderava em parceria com CA: estabeleciam as regras para organizar as tentativas e chamavam PE e JE ao trabalho, sendo que JE ficava sempre em último lugar para fazer seus testes. Contudo, houve um momento em que o grupo começou a trabalhar de forma mais cooperativa, apoiado nas dificuldades de seus membros e compartilhando objetivos comuns, mediante a superação do impasse sobre a exclusão do aluno JE do trabalho coletivo e seu respectivo avanço na construção de significados na aprendizagem em ciências.

Inicialmente, a professora lançou um convite para que o grupo funcionasse cooperativamente na resolução da atividade, explicitando seu desejo de fazer aceitar as contribuições de quem estava sendo excluído.

\begin{abstract}
Profa.: Neste encontro de hoje nós vamos tentar resolver um desafio. Temos um pote com água e outro de plástico. Observem. O desafio é o seguinte: como será que a gente fazpara colocar este papel dentro do copo e afundar o copo dentro da bacia com água, sem molhar o papel? Podem fazer do jeito que quiserem, conversem entre vocês, discutam as regras e pensem alguma forma para resolver este desafio. Mas não é só você ou ele, (aponta para CA e JA) o grupo todo deve conversar e explicar o fato.
\end{abstract}

Desde o primeiro encontro, a professora vislumbrava despertar o interesse e a participação dos alunos, embora ela não explicitasse essas finalidades para o grupo. Nesse encontro, ao contrário, a professora declarou para o grupo quanto, para ela, a colaboração grupal favorecia a qualidade do trabalho obtido, marcando sua entrada no discurso do conhecimento reflexivo. E este convite implícito forneceu abertura para novas escolhas entre os membros do grupo e a inclusão de JE.

Denunciando um pacto implícito: desde o primeiro encontro, os alunos JA, CA e PE constituíram um subgrupo; por sua vez, JE ficou excluído da discussão. JA se tornou a primeira liderança do grupo capaz de estabelecer uma identificação entre seus membros no sentido de constituir um bom grupo para a professora. Até este momento, JE mantinha-se em um patamar de demanda passiva. Ao mesmo tempo, houve, também, o estabelecimento de um pacto implícito do grupo em não deixar que as agressividades individuais perturbassem o trabalho conjunto; a lei estava em atender à demanda da professora, que ainda mantinha mais em evidência um discurso metodológico. Porém, neste sexto encontro, o aluno JE denunciou este pacto com a explicitação do impasse de sua exclusão.

JA: Vamos amassar o papel! Você concorda JE? Você concorda PE? Você concorda $C A$ ?

CA: Vamos decidir as regras primeiro. Calma aí! Primeiro (referindo-se ao aluno JA). Segundo (referindo-se ao aluno PE). Terceira (apontando para ela mesma) e quarto (referindo-se ao aluno JE).

JE: É, eu já sou o último mesmo! 
Mudanças subjetivas de um estudante ...

Este aluno recusou-se, em seguida, a realizar a atividade e permaneceu debruçado sobre a mesa, escondendo sua face. Ao perceber a atitude de JE e sua insatisfação em relação aos demais membros do grupo, a professora se aproximou e perguntou a ele.

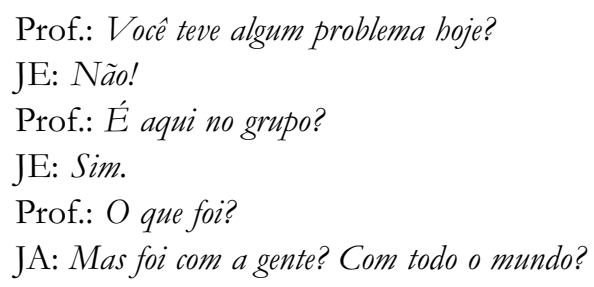

JE confirmou que era com o grupo todo acenando com a cabeça.

Prof.: Então peçam desculpas a ele!

JA: Mas do quê?

CA: $O$ que foi?

JA: O que aconteceu?

JE: Desde o começo!

Prof.: $O$ que foi que aconteceu?

JE: O JA fica falando que não quer que eu vá no grupo deles.

JA: Hoje eu não falei, professora. Faz tempo já.

JE: O dia que eu entrei no grupo ele disse assim, que não queria que eu entrasse no grupo deles.

JA: Não professora, mas sabe por que eu falei isso? É porque ele ficava brigando com todo mundo, a gente ficava falando pra ele pára e ele não parava, e dai uma hora eu cansei professora e falei, mas isso faz. tempo. [...] eu só fiquei com raiva quando ele ficava atrapalhando o grupo, atrapalhando todo mundo... dai eu falei.

A construção de um novo contrato: após JE manifestar sua insatisfação com o grupo, mediante ajuda da professora, o problema foi enfrentado por todos e o grupo superou o impasse, avançando em torno de uma produção conjunta. Os alunos refletiram o descontentamento do subgrupo em relação às atitudes de JE, sendo que esse também refletiu sobre suas atitudes. A exclusão de JE foi superada e os alunos comprometeram-se com a construção de novas regras, impuseram condições e compromissos para mudanças na tentativa de promover esta sustentação ao aluno JE.

PE: Se ele não fizer mais, não ficar brigando, en .... tudo bem.

JA: Aquele dia que a gente falou com ele, ele melhorou. Só que depois, continuou fazendo a mesma coisa, e também já faz tempo que eu falei isso, e porque ele tá assim só hoje?

CA: Mas, será que foi quando a gente decidiu quem ia comecar a resolver o desafio?

A aluna lembra-se do início da atividade quando definiram a ordem para realizarem as tentativas. JE permaneceu em silêncio por alguns instantes, de cabeça baixa, enquanto eles 
Barros, M. A.; Rocha, Z. F. D. C.; Laburú, C. E.

conversavam, e, em seguida, quando CA reforçava a fala de PE, ele levantou os olhos observando atentamente a proposta que parecia ser compartilhada por JA e PE.

CA: Se ele fizer a atividade e não brigar... A gente podia deixar ele tentar mais uma vez: Referia-se ao fato de oportunizar mais uma tentativa ao membro JE na resolução do desafio. E virando-se para JE perguntou: CA: Você aceita JE?

JE acenou com a cabeça indicando aceite. Então, o aluno JA chamou o grupo ao trabalho novamente, valorizando as tentativas e experiências de JE.

JA: Mas, então, eu quero ver o jeito que ele queria falar àquela hora na experiência.

Quando começaram a dialogar, as causas do problema apareceram, e, por meio das intervenções da professora, a situação foi se estabilizando aos poucos. Mas JE ainda sentia dificuldade para se expor, então, a professora, percebendo seu medo e fragilidade, sugeriu:

Profa.: Tente mesmo que não dê certo. É só para a gente ver como seria sua sugestão, como você mesmo disse: não importa se vai entrar água, mas que vocês mesmos estão tentando e aprendendo com isso, não é mesmo? Porque mesmo que entre água, nós podemos comparar o porquê entra água e porquê de outra forma não entra.

Logo em seguida, JA convocou o grupo na tentativa de acolher solidariamente JE.

JA: Vamos fazer assim... Depois que ele tentar do jeito dele, a gente começa a falar: Eu falo dum jeito, depois quem tiver uma idéia fala?!

Com o apoio do grupo e da professora, JE, confiante, voltou a realizar a tarefa ativamente, explicando suas ações e demonstrando tentativas diferentes. Nesse ponto é importante ressaltar que a professora agiu como um intermediário para as mudanças subjetivas de JE, que estava em um patamar de demanda passiva e passou a assumir novas atitudes frente ao trabalho - um patamar de risco em relação ao conhecimento.

\section{CA: Melhor você não dobrar assim. \\ JE: É que se não dobrar não cabe no copo. Pode ser que desse jeito dê certo!}

Conforme mencionamos anteriormente, o aluno JE não arriscava expor suas estratégias de trabalho para os outros membros do grupo, mas, depois da reelaboração do impasse entre eles, este aluno começou a avançar no processo de aprendizagem: justificava suas ações, analisava melhor os resultados obtidos e, paulatinamente, conquistava seu espaço no grupo. Por meio da provocação do diálogo conduzida pela professora, com intenções de formar um grupo, as mudanças consideradas necessárias à implantação de um novo clima de trabalho 
mais solidário e harmônico ocorreram diante do impasse instalado. Em suma, foi preciso uma desestabilização grupal para que o grupo sentisse a necessidade de refletir sobre a reação apresentada por JE. Desta forma, o dilema vivenciado por seus membros foi oportuno naquela situação na qual o grupo se encontrava, pois contribuiu para o seu desenvolvimento, um aspecto que favoreceu sua evolução em termos operativos. O grupo passou a se organizar não mais em torno do fantasma individual de um de seus membros, mas por uma imago de mãe boa e protetora trazida pela professora, o que garantiu maior estabilidade ao grupo e a inclusão definitiva do aluno JE que se encontrava periférico e pouco participativo.

Por sua vez, a professora "deu voz" ao grupo, mantendo o equilíbrio como coordenadora e fornecendo suporte para superação dos problemas, mas sem gerar dependência no sentido de poupar o grupo de assumir suas responsabilidades. A situação vivenciada fez com que a professora pudesse deslocar-se de seu discurso metodológico para o discurso do conhecimento reflexivo. Como os membros do grupo aderiram fortemente à demanda da professora, conseguiram estabelecer uma transferência do tipo simbólica ${ }^{7}$, e o aluno JE passou a ocupar um patamar de aprendizagem ativa, mesmo que em algumas situações pontuais, conforme nos revelam as ações e interações entre os membros do grupo e destes com a professora na sequência de fatos a seguir.

Prof.: Mas porque não está molhando?

JE: Porque a gente põe devagar e depois rápido.

Prof.: Por que molhou desta forma?

JE: Porque se pôr assim entra água. (demonstra novamente com o copo virado para o lado)

Prof.: E dai, terminaram?

JE: Não!

Prof.: Eu gostaria que vocês quatro conversassem, porque estou achando que vocês não estão pensando as mesmas coisas.

JA: O que você acha JE? JE passou a observar com atenção a aluna CA, que, neste momento, colocava metade do papel dentro do copo, bem amassado e preso, e a outra metade em cima do copo. Acompanhando a tentativa para a resolução do desafio, comunicou os fatos à professora).

Certamente, a captura pelo discurso do conhecimento reflexivo, pela professora, permitiu ao grupo encorajar-se e, progressivamente, aderir ao conhecimento de forma mais participativa, visando o respeito às ideias dos parceiros, em especial a inclusão de JE, e o avanço para níveis mais estáveis de organização.

\footnotetext{
${ }^{7}$ Ocorre quando o aluno opera uma mudança na sua relação com o saber, implicando a busca pela solução dos seus problemas, ainda que com a ajuda do professor. Ou seja, com sua autoridade, o professor deve garantir o resultado da operação iniciada pelo aluno, sustentando-o para não desistir do esforço.
} 
Barros, M. A.; Rocha, Z. F. D. C.; Laburú, C. E.

\section{Atividade dos cinco quadrados}

Esta atividade ocorreu no último encontro, e o desafio consistia em equilibrar, em uma haste vertical, cinco quadrados, um de cada vez, sendo quatro com arruelas fixadas em diferentes pontos de sua superfície e um sem nenhuma arruela.

O grupo de aprendizagem: desde o sexto encontro, a professora mantinha-se capturada pelo discurso do conhecimento reflexivo, sendo que, neste último encontro, podemos pontuar que os membros do grupo investigado constituíram-se como um grupo de aprendizagem, uma vez que procuraram solucionar o desafio em conjunto, no sentido de testarem suas ações, criarem novas estratégias, discutirem e compararem resultados, e analisarem caminhos para a resolução do desafio, além de fazerem relações com a vida cotidiana. Desta forma, avaliaram melhor suas experiências com o conhecimento abordado, refletindo sobre suas ações.

CA: Vai, vamos pôr! O grupo! Resolvemos assim! (vai relatando verbalmente e escrevendo)

JA: $O$ que a gente coloca?

PE: Que pegamos o quadrado e fomos equilibrando. (JA lê o texto que elaboravam coletivamente)

JA: Ó! Eu vou ler de novo, presta atenção! Ao final da leitura questiona: Pode pôr assim?

CA: Vai, põe...

JA: Dai como a gente pode contar...

JE: Espera ai que a CA tá falando.

JA: $O$ quê?

JE: Fala o que você ia falar! (CA argumenta sobre as tentativas para a resolução do problema realizadas pelo grupo, e JE confirma refazendo o experimento para exemplificar o relato)

JE: Ficou legal assim! Podemos também desenhar para mostrar melhor.

CA: A professora disse para relacionar com a nossa vida!

JE: É, coloca a gangorra, o equilibrista do circo... que tem haver com essa experiência... (relata os procedimentos e princípios análogos a outras experiências).

Percebe-se que, durante o relato, há um avanço importante na participação de JE no sentido de ocupar uma posição mais estável num patamar de aprendizagem ativa. Integrou-se de forma mais efetiva no grupo, passando a defender seus argumentos com maior segurança e acatando as opiniões dos demais.

\section{Comentários finais}

Neste trabalho, nosso objetivo consistiu em analisar as mudanças subjetivas de um estudante durante a realização de uma Oficina de Ciências, articulando-as com os discursos da professora e a dinâmica grupal. 
Inicialmente, destacamos a trajetória do estudante JE como associada à adesão a patamares subjetivos cada vez mais estáveis. Desde o primeiro encontro, posicionou-se num patamar de indecisão entre rejeitar um novo conhecimento ou aceitá-lo, mesmo que isso implicasse um trabalho mais colaborativo, passando para um patamar de demanda passiva com forte dependência da professora, onde o que estava em jogo era saber obter as respostas certas. A partir do sexto encontro, embora se mantivesse predominantemente numa demanda passiva em relação à professora, passou a aceitar uma situação de risco, chegando, de forma local, a vivenciar uma aprendizagem mais ativa. Tal posição de JE num patamar de aprendizagem ativa se consolidou no último encontro, no qual, efetivamente, trabalhou de forma cooperativa e se envolveu numa procura mais pessoal pelo conhecimento.

Quanto às intervenções da professora, cabe mencionar sua mudança de discurso, que passou do conhecimento metodológico para o conhecimento reflexivo, possibilitando a abertura por parte de JE de novas tentativas de inclusão no grupo e, ao mesmo tempo, convocandoo para uma participação mais efetiva. Nos primeiros encontros, além de lançar um convite para os estudantes vivenciarem uma nova experiência de aprendizagem, ela esteve muito mais preocupada em estabelecer as diretrizes do trabalho do que realmente promover uma integração de JE no grupo. Somente a partir do sexto encontro é que a professora tornou explícita, para os alunos, sua expectativa de que trabalhassem colaborativamente, incentivando JE a participar das discussões e sustentando sua entrada no grupo. Com a mudança de JE e do grupo para formas mais exitosas de trabalho colaborativo, passou a confiar ainda mais em sua estratégia de ensino, e sustentou as mudanças de JE para patamares mais estáveis de aprendizagem.

No que diz respeito à evolução do grupo, gostaríamos de caracterizar a existência de três momentos marcantes. O primeiro, que durou até o sexto encontro, no qual o grupo permaneceu estereotipado, mantendo uma estrutura fixa de papéis e realizando as tarefas de forma burocrática. Nesta etapa, o grupo organizou-se em torno do fantasma individual do seu líder e vivenciou a ilusão grupal ${ }^{8}$. A partir do sexto encontro em diante, a forma de organização grupal passou a ser estruturada não mais em torno de um fantasma individual, mas de uma imago de mãe boa. O grupo oscilou entre permanecer no esquema de funcionamento anterior ou mudar para uma outra posição mais colaborativa, permitindo que os estudantes se ajudassem mutuamente. Finalmente, no último encontro, pudemos observar a mudança do grupo para uma organização em torno de um fantasma originário, admitindo as diferenças entre seus membros, uma vez que tinham em comum algo mais definitivo, que era a origem. Dessa forma, os estudantes passaram a ocupar diferentes posições, com maior flexibilidade de papéis.

Podemos afirmar que, na terceira etapa, o grupo teve (e talvez tenha tido todo o tempo) como objeto de seu desejo satisfazer a demanda da professora, que era promover a operatividade do grupo e a contribuição de cada um. A partir da segunda etapa e, com mais

\footnotetext{
${ }^{8}$ A ilusão grupal é um conceito-chave na obra de Anzieu (1993), representa uma fase inevitável na formação dos grupos, sendo uma tentativa dos sujeitos de não experimentarem a situação de distinção entre "o grupo e eu". Daí a ênfase colocada no caráter caloroso das relações entre os membros de um grupo que vive a ilusão grupal.
} 
Barros, M. A.; Rocha, Z. F. D. C.; Laburú, C. E.

intensidade na terceira, a professora investiu esforços nessa direção. Diferentemente do que aconteceu na primeira etapa, na qual a resposta inconsciente dos alunos foi, em parte, de recusa, nesse momento, os alunos perderam o medo de serem aniquilados pela professora, desistiram da proteção exercida pela ilusão grupal e aceitaram se organizar em torno de algo que reatualizou um fantasma originário.

Analisando a história desse grupo, acreditamos que a dinâmica das atividades de ensino, os discursos da professora e a configuração entre os membros do grupo, progressivamente, exerceram particular importância em sua evolução no sentido de fornecerem sustentação e apoio para as mudanças subjetivas de JE para patamares de aprendizagem mais avançados.

Para finalizar, gostaríamos de destacar o fato da importância de o professor saber identificar os diferentes perfis subjetivos de seus alunos e utilizar uma metodologia de ensino mais flexível compatível com os tipos de patamares de aprendizagem que amarram os alunos numa determinada satisfação inconsciente. Isto implica a ruptura com planejamentos rígidos e atividades repetitivas, que se tornam obstáculos às mudanças dos alunos com a fixação em um determinado tipo de patamar menos ativo.

Dessa forma, esperamos poder contribuir para as pesquisas sobre formação de professores de ciências para as séries iniciais do Ensino Fundamental, no sentido de trazermos

alguns subsídios para a prática docente levando em consideração a influência de aspectos relacionados à subjetividade dos professores e alunos em situação de ensino.

\section{Referências}

ANZIEU, D. O grupo e o inconsciente: o imaginário grupal. São Paulo: Casa do Psicólogo, 1993.

ARRUDA, S. M. Entre a inércia e a busca: reflexões sobre a formação em serviço de professores de física do ensino médio. 2001. 230 f. Tese (Doutorado em educação) Faculdade de Educação, Universidade de São Paulo, São Paulo, 2001.

BAROLLI, E. Reflexões sobre o trabalho dos estudantes no laboratório didático. 1998. 191 f. Tese (Doutorado em educação) - Faculdade de Educação, Universidade de São Paulo, São Paulo, 1998.

BARROS, M. A. Análise de experiências didáticas com grupos de aprendizagem em física. 2002. 107 f. Tese (Doutorado em educação) - Faculdade de Educação, Universidade de São Paulo, São Paulo, 2002.

BARROS, M. A.; LABURÚ, C. E.; ROCHA, Z. F. D. C. Análise do vínculo entre grupo e professora numa aula de ciências do ensino fundamental. Ciência \& Educação, Bauru, v. 13, n. 2, p. 235-251, 2007. 
Mudanças subjetivas de um estudante ...

BARROS, M. A. et al. Analisando a dinâmica de um grupo de aprendizagem de ciências no ensino fundamental. In: CONGRESO INTERNACIONAL SOBRE INVESTIGACIÓN EN LA DIDÁCTICA DE LAS CIÊNCIAS, 7., 2005, Granada, Espanha. Anais... Granada, 2005. 1 CD-ROM.

BOGDAN, R.; BIKLEN, S. Investigação qualitativa em educação: uma introdução à teoria e aos métodos. Lisboa: Porto Editora, 1994. (Coleção Ciências da Educação).

CONFREY, J. A review of the research on student conceptions in mathematics, science and programming. Review of Research in Education, Itasca, v. 16, p. 3-56, 1990.

DUIT, R. Conceptual change: a powerful framework for improving science teaching and learning. International Journal of Science Education, London, v. 25, n. 6, p. 671-688, 2003.

DUVAL, R. A cognitive analysis of problems of comprehension in a learning of mathematics. Educational Studies in Mathematics, Dordrecht, v. 61, n. 1-2, p. 103-131, 2006.

FINK, B. O sujeito lacaniano: entre a linguagem e o gozo. Rio de Janeiro: Zahar, 1998.

FRANZONI, M. Os pontos de ressonância entre os convites docentes e a construção de saberes na formação inicial de professores. 2004. 153 f. Tese (Doutorado em educação)-Faculdade de Educação, Universidade de São Paulo, São Paulo, 2004.

KAËS, R. O grupo e o sujeito do grupo: elementos para uma teoria psicanalítica do grupo. São Paulo, Casa do Psicólogo, 1997.

LABURÚ, C. E.; CARVALHO, M. Educação científica: controvérsias construtivistas e pluralismo metodológico. Londrina: EDUEL, 2005.

LACAN, J. O Seminário. Livro 2: $o$ eu na teoria de Freud e na técnica da psicanálise. 4 ed. Rio de Janeiro: Ed. J. Zahar. 1995.

MOREIRA, M. A. A teoria dos campos conceituais de Vergnaud, o ensino de ciências e a pesquisa nesta área. Investigações em Ensino de Ciências, Porto Alegre, v. 7, n. 1, p. 7-30, 2002.

MORTIMER, E. Conceptual change or conceptual profile change. Science \& Education, Dordrecht, v. 4, n. 3, p. 267-285, 1995.

MORTIMER, E.; SCOTT, P. Atividade discursiva nas salas de aula de ciências: uma ferramenta sociocultural para analisar e planejar o ensino. Investigações em Ensino de Ciências, Porto Alegre, v. 7, n. 3, p. 283-306, 2002.

OSBORNE, R. J.; WITTROCK, M.C. Learning science: a generative process. Science Education, Salem, v. 67, n. 4, p. 489-508, 1983.

PINTRICH, P. R.; MARK, R. W.; BOYLE, R. A. Beyond cold conceptual change: the role of motivational beliefs and classroom contextual factors in the process of conceptual change. Review of Educational Research, Washington, v. 63, n. 2, p. 167-199, 1993. 
Barros, M. A.; Rocha, Z. F. D. C.; Laburú, C. E.

POSNER, G. J. et al. Accomodation of a scientific conception: toward a theory of conceptual change. Science Education, Salem, v. 66, n. 2, p. 211-227, 1982.

ROCHA, Z. F. D. C. Análise da dinâmica de um grupo de aprendizagem em ciências no ensino fundamental. 2005. 141 f. Dissertação (Mestrado em ensino de ciências e educação matemática) - Universidade Estadual de Londrina, Londrina, 2005.

SANTANA, D. A. Os discursos e suas possíveis implicações pedagógicas. 2003. 183 f. Dissertação (Mestrado em ensino de ciências)- - Instituto de Física, Universidade de São Paulo, São Paulo, 2003.

SOLOMON, J. Learning through experiment. Studies in Science Education, Leeds, v. 15, n. 1, p. 103-108, 1989.

STRIKE, K. A.; POSNER, G. J. A revisionistic theory of conceptual change. In: DUSCHL, R. A.; HAMILTON, R. J. (Ed.). Philosophy of science, cognitive psychology, and educational theory and practice. Albany: Suny Press, 1992. p. 147-176.

VALADARES, J. M. As formas e a construção da subjetividade em um grupo de professores: análise de uma prática e seus discursos. 2002. 183 f. Dissertação (Mestrado em educação) - Faculdade de Educação, Universidade de São Paulo, São Paulo, 2002.

VILLANI, A. e SANTANA, D.A. Analisando as interações dos participantes numa disciplina de Física. Ciência \& Educação, Bauru, v. 10, n. 2, p. 197-217, 2004.

VILLANI, A.; CABRAL, T. C. B. Mudança conceitual, subjetividade e psicanálise. Investigações em Ensino de Ciências, Porto Alegre, v. 2, n. 1, p. 43-81, 1997.

VILLANI, A.; BAROLLI, E. Interpretando a aprendizagem nas salas de encontro de ciências. In: REUNIÃO ANUAL DA ASSOCIAÇÃO NACIONAL DE PÓSGRADUAÇÃO E PESQUISA EM EDUCAÇÃO, 23., Caxambu, 2000. Atas... Caxambú: ANPED, 2000. 1 CD-ROM.

Artigo recebido em 26/09/2011. Aceito em 13/03/2012. 